\title{
Control of parturient behaviour by prostaglandin F-2 $\alpha$ in the tammar wallaby (Macropus eugenii)
}

\author{
G. Shaw \\ Department of Anatomy, Monash University, Clayton, Victoria 3168, Australia
}

\begin{abstract}
Summary. Nulliparous female tammar wallabies during the non-breeding season and adult male wallabies were treated with PGF-2 $\alpha$ at doses of $0.008,0.04,0.2$ and $1.0 \mathrm{mg} /$ $\mathrm{kg}$. All the male and female wallabies responded to the three highest doses by showing parturient behaviour. At the lowest dose $4 / 4$ males and 1/4 females responded. The peak concentrations of PGF- $2 \alpha$ metabolite (PGFM) in the peripheral plasma after administration of $0.008,0.04$ and $0.2 \mathrm{mg} \mathrm{PGF}-2 \alpha / \mathrm{kg}$ were $0.70 \pm 0.08,3.02 \pm 0.37$ and $8.48 \pm 0.76 \mathrm{ng} / \mathrm{ml}$ (mean \pm s.e.m.). Since the peak plasma concentrations of PGFM at normal parturition are reported to be $2.5 \pm 0.9 \mathrm{ng} / \mathrm{ml}$, parturient behaviour can be induced by physiological concentrations of exogenous PGF-2 $\alpha$. The effectiveness of PGF- $2 \alpha$ in males indicates that parturient behaviour is probably a result of a direct action of PGF- $2 \alpha$ on the brain, rather than a response to uterine or vaginal contractions. These experiments confirm that PGF- $2 \alpha$ is an important behavioural hormone in the tammar wallaby.
\end{abstract}

Keywords: PGF-2 $\alpha$; parturition; tehaviour; tammar wallaby; PGFM

\section{Introduction}

Parturient behaviour is normally only seen in pregnant wallabies, and begins only minutes before birth (Renfree et al., 1989). This characteristic and highly stereotyped behaviour is similar to that previously reported for the red kangaroo (Sharman \& Pilton, 1964; Sharman \& Calaby, 1964; Renfree et al., 1989). Over the 24-48 h before parturition females show an increased tendency to lick the pouch, cleaning out most of the normal accumulation of brown scale. Females lick the urogenital opening with increasing frequency over a few hours before birth, becoming most vigorous within 40-20 min of birth. Within $5 \mathrm{~min}$ of birth the females adopt the characteristic birth posture: the wallabies move their tails forward between their legs, and sit on their lower back with their hips rotated upwards, often resting backwards against a vertical support such as a fence or tree. The upper body is hunched forward, and they compulsively lick the urogenital opening, the pouch (often holding the pouch open with their forepaws), and the fur between the pouch and urogenital opening (Renfree et al., 1989). At this stage the females are completely preoccupied, and are undisturbed by the movements of other wallabies nearby. The intensity of licking declines gradually from about 10 min after birth, although females may remain in the birth posture for up to $1 \mathrm{~h}$ after birth (Sharman et al., 1966). Whilst tammars often sit with their tail forward between their legs when resting or cleaning their tails, the position adopted is much less extreme, and the females do not show the intense concentration that is seen at parturition (Renfree et al., 1989).

The hormonal controls for parturient behaviour are still uncertain, but the plasma concentrations of many hormones fluctuate rapidly close to the time of parturition in the tammar wallaby. Progesterone falls precipitously, and there is a brief pulse of prolactin and of PGFM, a major circulating metabolite of prostaglandin (PG) F-2 $\alpha$ (Shaw, 1983; Tyndale-Biscoe et al., 1983; Lewis et al., 1986). Plasma oestradiol rises to a peak soon after parturition, and post-partum oestrus 
usually occurs within $24 \mathrm{~h}$ after birth (Tyndale-Biscoe et al., 1983; Shaw \& Renfree, 1984). In nonpregnant animals, on the other hand, progesterone falls slowly, and there is no evidence of a pulse of prolactin or PGFM (Tyndale-Biscoe et al., 1983). Non-pregnant animals also return to oestrus about 1 day later than pregnant females (Merchant, 1979).

The rapid fall of plasma progesterone can play no part in inducing parturient behaviour, since treatment with progesterone at the end of pregnancy does not inhibit birth or prevent the neonates from successfully reaching the pouch (Ward \& Renfree, 1984). Rising oestradiol concentrations associated with the impending post-partum oestrus also play no role, since tammars can give birth without necessarily having a post-partum oestrus or elevated plasma oestradiol concentrations (Short et al., 1985; Shaw \& Renfree, 1984). In the swamp wallaby oestrus occurs 2-3 days pre partum (Calaby \& Poole, 1971), and in the grey kangaroo oestrus occurs 5-6 days post partum and is inhibited if the young successfully attaches to a nipple in the pouch (Poole, 1975).

In a recent study of the hormonal control of luteolysis in the tammar wallaby, we noticed that non-pregnant females injected with PGF-2 $\alpha$ on Days 23 and 26 of the cycle showed parturient behaviour within minutes (Hinds et al., 1990). This behaviour continued. for $>3 \mathrm{~h}$, quite unlike the very brief period seen at normal birth; the duration of birth behaviour corresponded with the period that PGFM levels were highest. This provided the first evidence that PGF-2 $\alpha$ might be involved in controlling birth behaviour. However, the doses of PGF- $2 \alpha$ administered were pharmacological, and it was unclear whether the effect was a direct one on the brain, or an indirect response to the PG-induced uterine and vaginal contractions (Shaw, 1983).

The present experiments were therefore designed to confirm this response using physiological doses of PGF-2 $\alpha$, and to eliminate the possible effects of uterine contractions by studying the behavioural responses of males and nulliparous females to PGF-2 $\alpha$ injection.

\section{Materials and Methods}

Animals and treatments. Four adult males and 4 nulliparous female tammar wallabies ( $<1$ year old) were used in these experiments during the non-breeding season to examine (1) the behavioural responses and (2) the profile of plasma PGFM concentrations after injection of PGF- $2 \alpha$.

Prostaglandin-F-2 $\alpha$ (Lutalyse, Upjohn Pty. Ltd, Rydalmere, NSW, Australia) was diluted in saline (0.15 M) immediately before injection, so that the administered dose was between 0.2 and $1.0 \mathrm{ml}$. Four doses were investigated, $1 \cdot 0,0 \cdot 2,0.04$ and $0.008 \mathrm{mg}$ PGF-2 $\alpha / \mathrm{kg}$, administered intramuscularly into the rump. Successive treatments with each of these doses for either behavioural or PGFM profile measurements were given in random order at intervals of $1-2$ weeks.

Behaviour. For behavioural observations the wallabies were placed in individual small pens with hessian screens around them to minimize disturbance. The animals were placed in these pens at least $2 \mathrm{~h}$ before treatment, and left undisturbed to allow them to habituate to their new environment. For injection each animal was caught, restrained briefly in a hessian sack whilst the injection was made into the thigh muscles, then immediately replaced in its small pen. All 8 wallabies received each of the 4 doses over successive experimental weeks, before treatment to determine the PGFM profiles. Observations continued until at least $\mathrm{I} \mathrm{h}$ after the last wallaby in the group had ceased to exhibit parturient behaviour. Time to onset of parturient behaviour (latency) was taken as the interval between PGF-2 $\alpha$ injection and the time when the wallaby first moved its tail forward between its legs. Termination of parturient behaviour was taken as the earliest observation of the wallaby in the standing (tail back) position when the animal did not revert to sitting with tail forward in the next $30 \mathrm{~min}$.

PGFM profiles. In tammars PGF- $2 \alpha$ is rapidly and quantitatively metabolized to 13,14-dihydro-15-ketoprostaglandin F-2 $\alpha$ (PGFM) (Shaw, 1983). Plasma PGFM concentrations therefore provide an easily measured index of plasma PGF-2 $\alpha$ values. In these experiments PGFM profiles were determined only for the lowest 3 doses of PGF-2 $\alpha$, since Hinds et al. (1990) have reported the PGFM profiles after a dose of $1 \mathrm{mg}$ PGF- $2 \alpha / \mathrm{kg}$.

Blood samples were taken through an intravenous catheter placed in the lateral tail vein before the start of PG treatment. The animals were restrained in hessian sacks from the time the catheter was implanted until the end of the sampling period, so no behavioural observations were made at this time. Catheters were flushed with $0.1 \mathrm{ml}$ heparinsaline and plugged between bleeds. Blood samples $(2 \mathrm{ml})$ were placed on ice, centrifuged and the plasma stored frozen $\left(-20^{\circ} \mathrm{C}\right)$ until assay. Blood samples were taken about every $15 \mathrm{~min}$ for $2 \mathrm{~h}$ after the $0.008 \mathrm{mg} / \mathrm{kg}$ dose. With the $0 \cdot 2$ and $0.04 \mathrm{mg} / \mathrm{kg}$ doses peripheral venoconstriction made sampling difficult, and so blood samples were obtained only every $20-30 \mathrm{~min}$ from each animal in rotation. 
PGFM assay. Plasma PGFM was measured by the method of Lewis et al. (1986) using antiserum kindly provided by Professor A. P. F. Flint (London, UK). Inter- and intra-assay coefficients of variance were 11.2 and $9.6 \%$ respectively. All samples from each animal at each dose were measured in a single assay.

Statistics. The half-life of PGFM in the wallabies was determined from the linear regression of the logarithm of the PGFM concentration against time from injection between 10 and 100 min after injection. No significant curvature of this graph was seen in this time period (Fig. 2).

The times of the first blood sample after injection differed greatly between animals and between the dose groups. To remove this potential bias on the peak PGFM concentrations measured, predicted peak PGFM concentrations in males and females were determined by extrapolating the plasma PGFM concentration back to $10 \mathrm{~min}$ after injection. This standardized concentration, PGFM ${ }_{10}$, and the highest value observed (uncorrected) were tested by analysis of variance after logarithmic transformation to establish the effects of dose given and the sex of the treated animal. Latency to enter birth position, and duration of this behaviour were compared between doses using non-parametric two-way analysis of variance (Friedman, 1937), and Page's test for ordered alternatives (Page, 1963).

Average values are reported as mean \pm s.e.m. unless stated otherwise.

\section{Results}

\section{Behaviour}

Adult males and nulliparous females responded to PGF-2 $\alpha$ injection by showing parturient behaviour (Fig. 1). All animals responded to the three highest doses. With the lowest dose, all of the males but only 1 of the 4 females responded.

The pattern of behaviour was similar to that previously described for normal parturient females, with the major difference that the males licked their scrotum whereas the females licked their pouches. Soon after injection the wallabies began grooming of the forearms, abdomen and flanks. Within 1-2 min grooming became focussed on the pouch or scrotum, urogenital opening and the abdominal fur between. At about the same time they moved into the birth posture, with the tail forward, hips rotated upwards, and the body hunched forward (Fig. 1). Particularly with the higher doses, the animals at this stage were very intent on their activities and were so undisturbed by external stimuli that they could be approached and even touched by the observer without them leaving the birth posture. Under similar conditions untreated wallabies are very apprehensive and move away when an observer approaches.

The interval between injection and onset of parturient behaviour (latency) decreased with increasing doses (Table 1; $P<0 \cdot 05$, Page's test). The duration of birth behaviour was also doserelated, decreasing with lower doses (Table $1 ; P<0.05$, Page's test). No statistically significant differences were seen in the timing of these responses between males and females $(P>0 \cdot 2)$. Licking of the pouch/scrotum and urogenital openings was initially continuous, but became discontinuous. Grooming bouts became progressively less frequent, and the wallabies became increasingly responsive to external disturbances as time passed. With the lowest dose the wallabies never became as intent on birth behaviour, and remained relatively alert to external disturbances.

The only other behavioural effect of PGF- $2 \alpha$ injection noted was panting respiration, which was seen in all animals for a period corresponding roughly to when they were most intent on birth behaviour.

\section{PGFM concentrations}

With all doses, peak plasma PGFM concentrations were observed within about 10 min of injection (Fig. 2). Plasma PGFM declined after this peak in an approximately exponential manner. The half life was $39.6 \pm 3.4 \mathrm{~min}$, and did not differ significantly between males or females, or between doses $(P>0.05)$.

Peak PGFM concentrations and PGFM $_{10}$ (Table 2) were similar in males and females $(P>0.20)$, but were dose-dependent $(P<0.0001)$. 

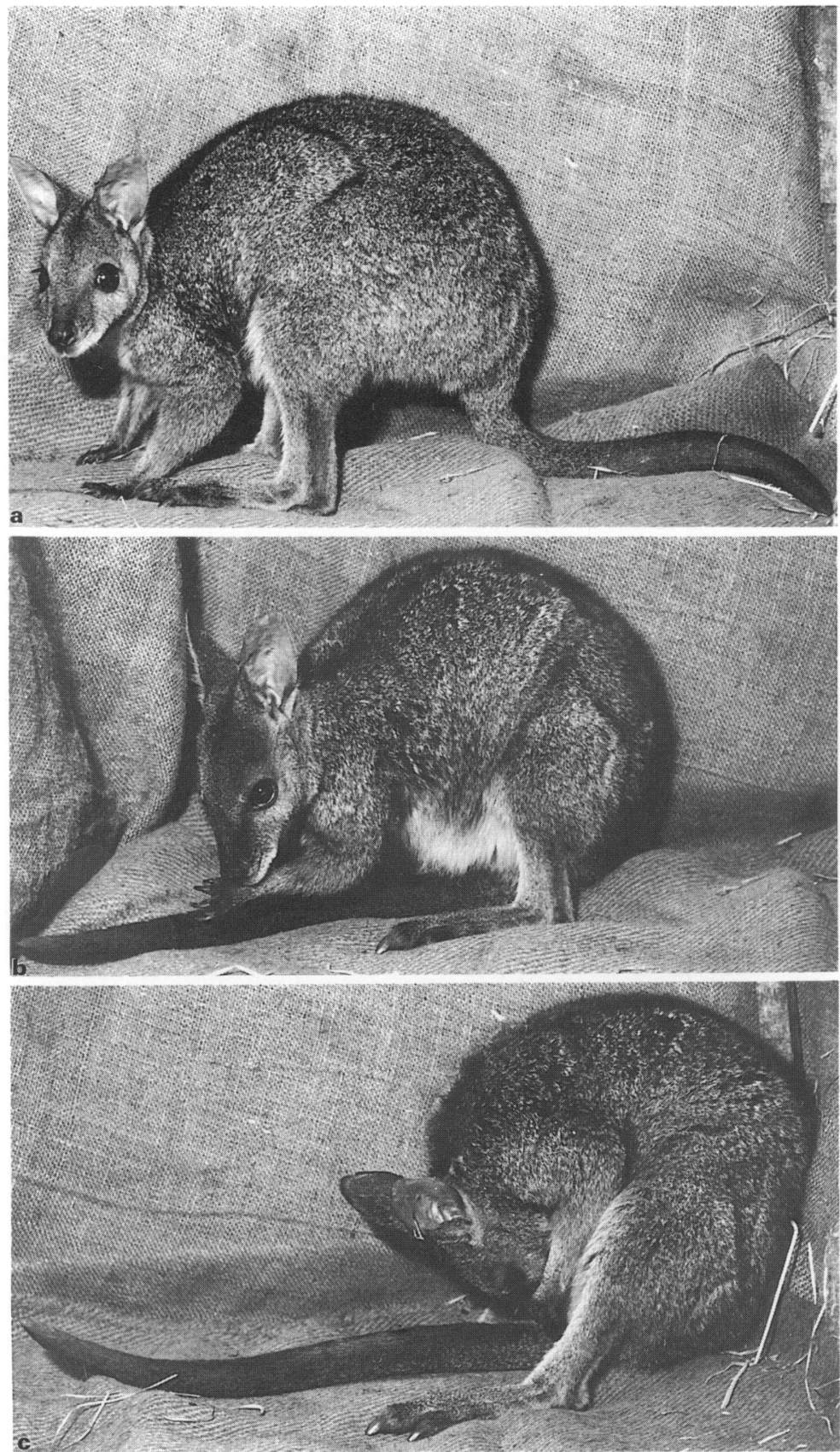

Fig. 1. Behavioural sequence in a male tammar wallaby injected with $0.04 \mathrm{mg} P G F-2 \alpha / \mathrm{kg}$. (a) Normal posture before injection. Note that the wallaby is alert and easily disturbed by the observer. (b) At 12 min after injection the wallaby has moved his tail forward between his legs and is licking his forearms. (c) At $20 \mathrm{~min}$ after injection the wallaby is in the birth position, with his back supported by the side of the cage, and his hips rotated upwards. The animal is vigorously licking his lower abdominal region and is not easily disturbed by the observer. 
Table 1. Latency to, and duration of birth behaviour in tammars treated with different doses of PGF-2 $\alpha$

\begin{tabular}{lccr}
\hline $\begin{array}{l}\text { PGF-2 } \alpha \\
\text { dose } \\
(\mathrm{mg} / \mathrm{kg})\end{array}$ & $\begin{array}{c}\text { No. of } \\
\text { tammars }\end{array}$ & $\begin{array}{c}\text { Latency to } \\
\text { birth behaviour } \\
(\mathrm{min})\end{array}$ & $\begin{array}{c}\text { Duration of } \\
\text { birth behaviour } \\
(\mathrm{min})\end{array}$ \\
\hline 0.008 & 5 & $98.6 \pm 30.8$ & $60 \cdot 0 \pm 26 \cdot 0$ \\
0.04 & 8 & $15.0 \pm 4.4$ & $89.6 \pm 27.9$ \\
0.2 & 8 & $5.9 \pm 0.9$ & $152.6 \pm 31 \cdot 1$ \\
1.0 & 8 & $4.4 \pm 0.6$ & $211.4 \pm 23.6$ \\
\hline
\end{tabular}

Values are mean \pm s.e.m.

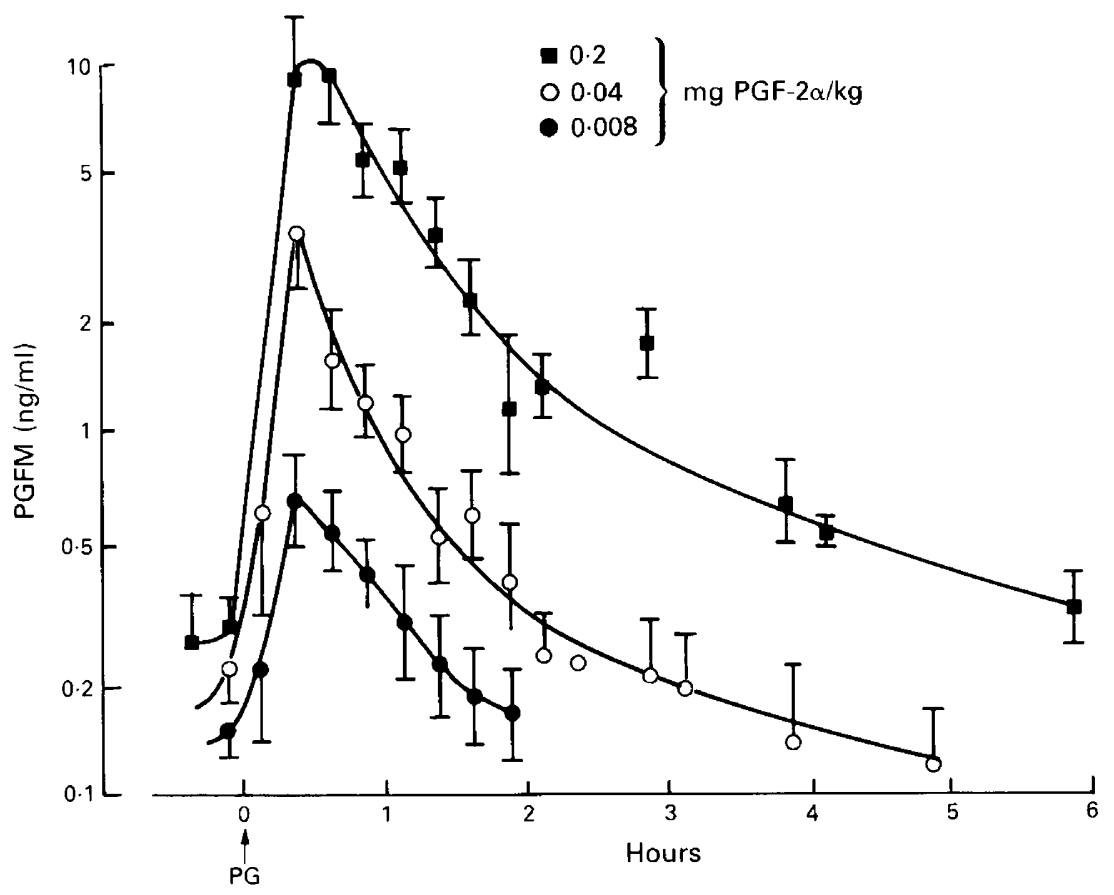

Fig. 2. Plasma PGFM concentrations in tammars after injection of PGF- $2 \alpha$ (arrow). Values are mean \pm s.e.m. for all samples taken in each 15-min interval for each PGF-2 $\alpha$ dose.

Table 2. Peak plasma PGFM concentrations in tammars $(\mathrm{N}=8 /$ group) given different doses of PGF- $2 \alpha$

\begin{tabular}{lccc}
\hline $\begin{array}{l}\text { PGF-2 } \alpha \\
\text { dose } \\
(\mathrm{mg} / \mathrm{kg})\end{array}$ & $\begin{array}{c}\text { Predicted } \\
\text { PGFM }_{10} \\
(\mathrm{pg} / \mathrm{ml})\end{array}$ & $\begin{array}{c}\text { Peak } \\
\text { PGFM } \\
(\mathrm{pg} / \mathrm{ml})^{*}\end{array}$ & $\begin{array}{c}\text { Sampling time } \\
\text { (min after } \\
\text { injection) }\end{array}$ \\
\hline 0.008 & $0.71 \pm 0.08$ & $0.70 \pm 0.08$ & $12 \pm 3$ \\
0.04 & $3.94 \pm 0.57$ & $3.02 \pm 0.37$ & $22 \pm 4$ \\
0.2 & $14.15 \pm 1.43$ & $8.48 \pm 0.76$ & $33 \pm 3$ \\
\hline
\end{tabular}

Values are mean \pm s.e.m.

*Peak value in first sample taken after injection, and the interval between injection and taking of that sample. 


\section{Discussion}

Prostaglandins have been shown previously to influence sexual behaviours in a wide range of vertebrates, from fish (Stacey, 1987) to mammals (Rodriguez-Sierra \& Komisaruk, 1978, 1982), and the effects may be inhibitory or stimulatory. In general, in animals in which vaginal or oviducal stimulation increases sexual receptivity, prostaglandins mimic this response (goldfish: Stacey \& Peter, 1979; paradise fish: Villars et al., 1985; leopard frog; Diakow \& Nemiroff, 1981; South African clawed toad: Weintraub et al., 1985; rat: Rodriguez-Sierra \& Komisaruk, 1978, 1982; hamster: Buntin \& Lisk, 1979). Conversely, in animals in which vaginal stimulation or mating inhibit female sexual receptivity, prostaglandins are inhibitory (green anole lizard: Tokarz \& Crews, 1981; garter snake: Whittier \& Crews, 1986; guinea-pig: Marrone et al., 1979). The behavioural responses appear to be induced by a direct action in the brain (Stacey \& Peter, 1979; Diakow \& Raimondi, 1981; Rodriguez-Sierra \& Komisaruk, 1982).

Injection of PGF-2 $\alpha$ into non-pregnant sows induces the main elements of nest building, a major maternal behaviour (Blackshaw \& Blackshaw, 1982). These authors believed this was an indirect behavioural effect of prolactin, since PGF- $2 \alpha$ induces an immediate rise in plasma prolactin (Taverne et al., 1979), and prolactin induces maternal behaviour patterns in rats (Riddle $e t$ al., 1935). In tammars PGF-2 $\alpha$ injection also induces an immediate rise in plasma prolactin. However, this rise in prolactin cannot be responsible for the birth behaviour seen, since injection of prolactin alone has no obvious behavioural sequelae (Hinds et al., 1990).

In tammar wallabies at the end of pregnancy there is evidence for an increased synthesis of prostaglandins by the gravid uterus (Shaw, 1983). At parturition there is a brief peak of PGFM in the plasma, presumably as a result of an acute increase in uterine PGF-2 $\alpha$ release (Shaw, 1983; Lewis et al., 1986). Whether this increase causes, or is a result of, the increased uterine and vaginal contractions associated with birth is not yet known. However, the brief pulse of PGF- $2 \alpha$ release could serve as a very suitable hormonal cue for the birth behaviour which is normally only seen at the time of parturition (Renfree et al., 1989).

In tammars PGF-2 $\alpha$ is rapidly metabolized to PGFM, and concentrations of PGFM in the plasma provide a useful index of PGF-2 $\alpha$ release (Shaw, 1983). Since the peak plasma PGFM concentrations in tammars injected with $0.04 \mathrm{mg}$ PGF $-2 \alpha / \mathrm{kg}$ are similar to the peak concentrations of $2.5 \pm 0.9 \mathrm{ng} / \mathrm{ml}$ seen in parturient wallabies (Lewis et al., 1986), this dose can be regarded as physiological. Consistent with this, the only animals not exhibiting parturient behaviour were those in the lowest dose group $0.008 \mathrm{mg}$ PGF $-2 \alpha / \mathrm{kg}$, in which the peak PGFM concentrations were $0.70 \pm 0.08 \mathrm{ng} / \mathrm{ml}$, substantially below those in parturient animals.

Co-ordination of birth and maternal behaviour by prostaglandins may not be limited to marsupials. In sheep, vaginal-cervical stimulation can induce a full complement of maternal behaviour (Keverne et al., 1983) and mother-infant bonding (Poindron et al., 1986), and such stimulation would almost certainly cause significant release of prostaglandins from the vaginal and cervical tissues. However, prolactin may also be important in this behaviour (Poindron et al., 1980).

The pouch skin of wallabies is usually coated with a brown waxy secretion, which normally disappears as pouch cleaning activity increases over the 2-3 days preceding parturition. Since such pouch cleaning is not usually seen in non-pregnant wallabies, it is possible that this behavioural change is a result of small pulses of PGF- $2 \alpha$ from the gravid uterus which are insufficient to induce a full birth-behavioural response. One of the first effects of injected PGF- $\alpha$ was grooming of the abdominal region including the pouch (or scrotum), with adoption of the birth position soon after.

A remarkable aspect of the behavioural response to PGF- $2 \alpha$ in tammars is that it occurs so readily in males and nulliparous females in the non-breeding season. In other species most sexual behaviours are dependent on an appropriate priming with appropriate sex steroids, and the expression can also be influenced by prior experience (Rosenblatt et al., 1979). The responses of males of other species may also differ from those of females. Thus, PGF- $2 \alpha$ induces nesting behaviour in 
sows, but copulatory behaviour in boars (Blackshaw \& Blackshaw, 1982), whilst in goldfish PGF-2 $\alpha$ will induce female-type spawning behaviour in males (Stacey, 1987).

This study confirms that PGF-2 $\alpha$ injection induces parturient behaviour in physiological doses. Since this effect is seen in non-breeding nulliparous females, and in adult males, it seems unlikely to be an indirect effect of PG-stimulated uterine or vaginal contractions. It is therefore most likely that PGF- $2 \alpha$ induces birth behaviour by a direct action in the brain.

I thank Dr T. P. Fletcher and Ms S. Williams for assistance in animal handling and blood sampling; Dr A. P. F. Flint for the PGFM antiserum; and Dr M. B. Renfree and Professor R. V. Short for helpful comments. These studies were supported in part by an ARC grant to Professor R. V. Short and Dr M. B. Renfree. Animals were held under permit 84/28 from the Department of Conservation, Forest and Lands, Victoria, Australia.

\section{References}

Blackshaw, J.K. \& Blackshaw, A.W. (1982) The effects of prostaglandin (PGF-2 $\alpha$ ) on the behaviour of the domestic non-pregnant sow and boar. Animal Production in Australia 14, 550-552.

Buntin, J.D. \& Lisk, R.D. (1979) Prostaglandin $E_{2}$ induced lordosis in estrogen-primed female hamsters: relationship to progesterone action. Physiol. Behav. 23, 569-575.

Calaby, J.H. \& Poole, W.E. (1971) Keeping kangaroos in captivity. Int. Zoo Yb. 11, 5-12.

Diakow, C. \& Nemiroff, A. (1981) Vasotocin, prostaglandin, and female reproductive behaviour in the frog, Rana pipens. Horm. \& Behav. 15, 86-93.

Diakow, C. \& Raimondi, D. (1981) Rana pipens reproductive behaviour: a proposed mechanism for inhibition of the release call. Am. Zool. 21, 295-304.

Friedman, M. (1937) The use of ranks to avoid the assumption of normality implicit in the analysis of variance. $J$. Am. Statist. Assoc. 32, 675-701.

Hinds, L. A., Tyndale-Biscoe, C.H., Shaw, G., Fletcher, T.P. \& Renfree, M.B. (1990) Effects of prostaglandin and prolactin on luteolysis and behaviour in the tammar, Macropus eugenii. J. Reprod. Fert. 88, 323-333.

Keverne, E.B., Levy, F., Poindron, P. \& Lindsay, D.R. (1983) Vaginal stimulation: an important determinant of maternal bonding in sheep. Science, $N Y 219,81-83$.

Lewis, P.R., Fletcher, T.P. \& Renfree, M.B. (1986) Prostaglandin in the peripheral plasma of tammar wallabies during parturition. J. Endocr. 111, 103-109.

Marrone, B.L., Rodriguez-Sierra, J.F. \& Feder, H.H. (1979) Differential effects of prostaglandins on lordosis in female guinea pigs and rats. Biol. Reprod. 20, 853-861.

Merchant, J.C. (1979) The effect of pregnancy on the interval between one oestrus and the next in the tammar wallaby, Macropus eugenii. J. Reprod. Fert. 56, 459-463.

Page, E.B. (1963) Ordered hypotheses for multiple treatments: a significance test for linear ranks. J. Am. Statist. Assoc. 58, 216-230.

Poindron, P., Orgeur, P., Le Neindre, P., Kann, G. \& Raksanyi, I. (1980) Influence of the blood concentration of prolactin on the length of the sensitive period for establishing maternal behaviour in the sheep at parturition. Horm. \& Behav. 14, 173-177.
Poindron, P., Levy, F., Le Neindre, P. \& Keverne, E.B. (1986) The roles of genital stimulation, oestrogens and olfaction in the maternal bonding of sheep and other animals. In Hormones and Behaviour, pp. 538-548. Eds L. Dennerstein \& I. Fraser. Elsevier Science Publishers B.V. (Biomedical Division), Amsterdam.

Poole, W.E. (1975) Reproduction in the two species of grey kangaroo, Macropus giganteus Shaw, and $M$. fuliginosis (Desmarest). II. Gestation, parturition and pouch life. Aust. J. Zool. 23, 333-353.

Renfree, M.B., Fletcher, T.P., Blanden, D.R., Lewis, P.R., Shaw, G., Gordon, K., Short, R.V., Parer-Cook, E. \& Parer, D. (1989) Physiological and behavioural events around the time of birth in macropodid marsupials. In Kangaroos, Wallabies and Rat Kangaroos, pp. 323-337. Eds G. Grigg, P. Jarman \& I. D. Hume. Surrey Beaty \& Sons, Chipping Norton.

Riddle, O., Bates, R.W. \& Lahr, E.L. (1935) Maternal behaviour induced in virgin rats by prolactin. Proc. Soc. exp. Biol. Med. 32, 730-734.

Rodriguez-Sierra, J.F. \& Komisaruk, B.R. (1978) Lordosis induction in the rat by prostaglandin $E_{2}$ systemically or intracranially in the absence of ovarian hormones. Prostaglandins 15, 513-525.

Rodriguez-Sierra, J.F. \& Komisaruk, B.R. (1982) Common hypothalamic sites for activation of sexual receptivity in female rats by $\mathrm{LHRH}, \mathrm{PGE}_{2}$ and progesterone. Neuroendocrinology 35, 363-369.

Rosenblatt, J.S., Siegel, H.I. \& Mayer, A.D. (1979) Progress in the study of maternal behaviour in the rat: hormonal, nonhormonal, sensory and developmental aspects. Advances in the Study of Behaviour 10, 225-311.

Sharman G.B. \& Calaby, J.H. (1964) Reproductive behaviour in the red kangaroo, Megaleia rufa, in captivity. CSIRO Wildlife Research 9, 58-85.

Sharman, G.B. \& Pilton, P.E. (1964) The life history and reproduction in the red kangaroo (Megaleia rufa). Proc. zool. Soc. Lond. 142, 29-48.

Sharman, G.B., Calaby J.H. \& Poole, P.E. (1966) Patterns of reproduction in female diprotodont marsupials. Symp, zool. Soc. Lond. 15, 205-232.

Shaw, G. (1983) Effect of PGF-2 $\alpha$ on uterine activity and concentration of 13,14-dihydro-15-keto-PGF-2 $\alpha$ in peripheral plasma during parturition in the tammar 
wallaby (Macropus eugenii). J. Reprod. Fert. 69, 429-436.

Shaw, G. \& Renfree, M.B. (1984) Concentrations of oestradiol-17ß in piasma and corpora lutea throughout pegnancy in the tammar, Macropus eugenii. $J$. Reprod. Fert. 72, 29-36.

Short, R.V., Flint, A.P.F. \& Renfree, M.B. (1985) Influence of passive immunization against GnRH on pregnancy and parturition in the tammar wallaby, Macropus eugenii. J. Reprod. Fert. 75, 567-575.

Stacey, N.E. (1987) Role of hormones and pheromones in fish reproductive behaviour. In Psychobiology of Reproductive Behavior, pp. 28-60. Ed. D. Crews. Prentice Hall Inc., Englewood Cliffs.

Stacey, N.E. \& Peter, R.E. (1979) Central action of prostaglandins in spawning behaviour of female goldfish. Physiol. Behav. 22, 1191-1196.

Taverne, M., Willemse, A.H., Dielman, S.J. \& Bevers, M. (1979) Plasma prolactin progesterone and oestradiol$17 \beta$ concentrations around parturition in the pig. Anim. Reprod. Sci. 1, 257-263.

Tokarz, R.R. \& Crews, D. (1981) Effects of prostaglandins on sexual receptivity of the female lizard, Anolis carolinensis. Endocrinology 109, 451-457.
Tyndale-Biscoe, C.H., Hinds, L.A., Horn, C.A. \& Jenkins, G. (1983) Hormonal changes at oestrus, parturition and post-partum oestrus in the tammar wallaby (Macropus eugenii). J. Endocr. 96, 155-161.

Villars, T.A., Hale, N. \& Chapnick, D. (1985) Prostaglan$\operatorname{din} \mathbf{F}_{2 a}$ stimulates reproductive behaviour of female paradise fish, Macropodus opercularis (L.) (Osteichthyes: Belontiidae). Physiol. Behav. 19, 371-375.

Ward, K.L. \& Renfree, M.B. (1984) Effects of progesterone on parturition in the tammar, Macropus eugenii. J. Reprod. Fert. 72, 21-28.

Weintraub, A.S., Kelly, D.B. \& Bockman, R.S. (1985) Prostaglandin E2 induces receptive female behaviour in female Xenopus laevis. Horm. \& Behav. 19, 386-399.

Whittier, J.M. \& Crews, D. (1986) Effects of prostaglan$\operatorname{din} \mathrm{F}-2 \alpha$ on sexual behaviour and ovarian function in female garter snakes (Thamnophis sirtalis parietalis). Endocrinology 119, 787-792.

Received 27 June 1989 